\title{
Association of vitamin D supplementation with serum leptin and metabolic parameters in Egyptian patients with non- alcoholic steatohepatitis: a prospective study
}

Hany Haroun Kaisar * (1) and Ahmed Samir Abo Halima

\begin{abstract}
Background: Nonalcoholic steatohepatitis (NASH) is the progressive form of NAFLD, a common cause of liver disease, with increased chance of progression to liver fibrosis, cirrhosis, and hepatocellular carcinoma. Circulating leptin is increased in patients with NASH. It is an independent positive predictor of the severity of hepatic steatosis. Vitamin D is a lipophilic molecule essential to maintain calcium and phosphate balance. Moreover, it has antifibrotic, antiproliferative, and anti-inflammatory effects on the liver. Vitamin D deficiency is a worldwide condition and very common in patients with NASH. Low serum vitamin D has been shown to predispose to intrahepatic lipid accumulation leading to NAFLD. The aim of this study was to investigate the association of vitamin D supplementation with serum leptin and metabolic parameters in Egyptian patients with non-alcoholic steatohepatitis

Results: Patients with NASH group had statistically significant higher values of diastolic blood pressure $(94.3 \pm 11.9$ $\mathrm{mmHg}, p<0.0001)$, glycated hemoglobin $(8.0 \pm 2.4 \%, p<0.0001)$, fasting blood sugar $(165.6 \pm 62.0 \mathrm{mg} / \mathrm{dL}, p<0.0001)$, fasting insulin level $(24.2 \pm 3.0 \mu \mathrm{U} / \mathrm{ml}, p<0.0001)$, homeostatic model assessment of insulin resistance (HOMA-IR) (1.8 \pm $0.7, p<0.0001)$, alanine transferase (ALT) $(78.2 \pm 36.7 \mathrm{U} / \mathrm{L}, p<0.0001)$, aspartate transferase (AST) $(108.6 \pm 85.6 \mathrm{U} / \mathrm{L}, p<$ $0.0001)$, NAFLD fibrosis score $(-0.78 \pm 0.9, p<0.0001)$, total cholesterol $(233.0 \pm 40.9 \mathrm{mg} / \mathrm{dL}, p=0.0011)$, low-density lipoprotein $(117.5 \pm 41.6 \mathrm{mg} / \mathrm{dL}, p=0.0084)$, and triglycerides $(229.7 \pm 62.1 \mathrm{mg} / \mathrm{dL}, p<0.0001)$ than the control group. Moreover, they had lower serum vitamin D level $(15.6 \pm 6.6 \mathrm{ng} / \mathrm{ml}, p=0.0004)$ and higher serum leptin level $(35.9 \pm$ $28.4 \mathrm{ng} / \mathrm{ml}, p<0.0001)$ than the control group. Following vitamin $D$ supplementation, there was a statistically significant reduction in $\mathrm{HbA1c}(6.8 \pm 1.3 \%, p=0.0055)$, fasting blood sugar (136.1 $\pm 32.7 \mathrm{mg} / \mathrm{dL}, p=0.0094)$, fasting insulin level (22.9 $\pm 1.8 \mu \mathrm{U} / \mathrm{ml}, p=0.0236)$, HOMA-IR (1.4 $\pm 0.4, p=0.0026)$, ALT (55.3 $\pm 21.3 \mathrm{U} / \mathrm{L}, p=0.0010)$, AST (73.1 $\pm 54.2 \mathrm{U} / \mathrm{L}, p=0.0297)$, and triglycerides $(203.6 \pm 49.8 \mathrm{mg} / \mathrm{dL}, p=0.0415)$ in patients with NASH. There was a statistically significant increase in serum vitamin $D$ level $(33.0 \pm 7.6 \mathrm{ng} / \mathrm{ml}, p<0.0001)$ and decrease in serum leptin level $(23.5 \pm 12.9 \mathrm{ng} / \mathrm{ml}, p=0.0140)$ after treatment.

(Continued on next page)
\end{abstract}

* Correspondence: dr_hanyharoun@yahoo.com

Gastroenterology and Hepatology Department, Faculty of Medicine, Ain

Shams University, Cairo 11211, Egypt 
(Continued from previous page)

Conclusions: Vitamin D supplementation in patients with NASH in a dose of $4000 \mathrm{IU} /$ day for 12 weeks improves severity of hepatic inflammation, decreases insulin resistance, improves glycemic control, corrects dyslipidemia, and protects against lipotoxicity by inhibition of serum leptin.

Keywords: Vitamin D, Nonalcoholic fatty liver disease, Nonalcoholic steatohepatitis, Leptin

\section{Background}

Nonalcoholic fatty liver disease (NAFLD) is considered as the most common cause of liver disease [1]. It is a condition histologically characterized by macrovesicular hepatic steatosis in individuals who do not consume alcohol in amounts generally considered to be harmful to the liver [2]. It is a broad term consisting of patients with simple steatosis or nonalcoholic fatty liver (NAFL) at one end of the spectrum, nonalcoholic steatohepatitis (NASH), NASH-related cirrhosis, and hepatocellular carcinoma (HCC) at the other end [3].

NAFLD is reported to be associated with other systemic diseases, such as cardiovascular diseases, insulin resistance (IR), obesity, dyslipidemia, and metabolic syndrome (MS) [4]. The prevalence of NAFLD is increasing and has been estimated to be between 10 and $30 \%$ worldwide [5].

Nonalcoholic steatohepatitis (NASH) is the progressive form of NAFLD characterized by lobular inflammation, hepatocyte degeneration, and ballooning, under the condition of macrovesicular hepatic steatosis. The danger of this specific form of NAFLD is expressed by its increased chance of progressing to liver fibrosis, cirrhosis, and hepatocellular carcinoma [6].

Leptin is a 167-amino acid protein produced by adipocytes in the hypothalamus [7]. Leptin is proportionally released to the amount of fat stored in the white adipose tissue and acts in hypothalamic suppression of food intake and increase in energy expenditure [8]. Circulating leptin is increased in both men and women with NASH. Serum leptin is an independent positive predictor of the severity of hepatic steatosis [9].

Vitamin D is a lipophilic molecule essential to maintain calcium and phosphate balance and osteometabolic system regulation [10]. Vitamin D also has antifibrotic, antiproliferative, and anti-inflammatory effects on the liver [11].

Vitamin D deficiency is also a worldwide condition and is present in approximately $30-60 \%$ of the general adult population [12]. Vitamin D-deficient individuals are more likely to develop alterations in glucose metabolism, such as impaired glucose tolerance, metabolic syndrome (MS), and type 2 diabetes mellitus (DM) [13]. Vitamin D levels have been reported to be inversely related with fasting glucose concentrations [14], adiposity [15], and blood pressure [16]. Low serum vitamin D has been shown to predispose to intrahepatic lipid accumulation leading to NAFLD as vitamin D is capable of reducing free fatty acid (FFA)-induced insulin resistance (IR) both in peripheral tissues and in hepatocytes [17].

Because NAFLD and vitamin D deficiency have similar risks for cardiovascular disease, insulin resistance, and metabolic syndrome in epidemiologic studies, there have been many reports debating a potential association between NAFLD and vitamin D deficiency [18].

Vitamin D substitution thus may represent a simple, cheap, and almost side effect-free approach to reduce the burden of end-stage liver failure and liver cancer in $\mathrm{NASH}$ as medical interventions with proven long-term efficacy are still lacking [19]. Vitamin D may influence hepatocytes and non-parenchymal hepatic cells (hepatic stellate cells, Kupffer cells) in NASH via metabolic, antiinflammatory, and anti-fibrotic effects [20]. Several inflammatory cytokines, such as interleukin-6 (IL-6), tumor necrosis factor alpha (TNF- $\alpha$ ), and IL-1 $\beta$, and adipokines, such as adiponectin and leptin, may participate in these reactions [21].

The aim of this study was to investigate the association of vitamin D supplementation with serum leptin and metabolic parameters in Egyptian patients with nonalcoholic steatohepatitis.

\section{Methods}

This study was carried out in the Hepatology and Gastroenterology Department, Faculty of Medicine, Ain Shams University. The study included 40 patients with NASH referred to the hepatology clinic during the period between January 2019 and June 2019 in addition to 40 age- and sex-matched healthy individuals which were taken as the control group. All participants agreed to the study conditions and provided a written informed consent before enrollment in this study.

Inclusion criteria for patients with NASH included age more than 16 years, either total abstainers or consumption of less than $20 \mathrm{gm}$ of alcohol per day, ultrasound showing features of steatosis, raised serum ALT level more than $40 \mathrm{IU} / \mathrm{L}$ for at least 6 months before enrollment in the study, negative viral markers (hepatitis $\mathrm{B}$ surface antigen and anti-hepatitis $C$ virus), negative autoimmune markers (antinuclear antibody, anti-smooth muscle antibody, and antimitochondrial antibody), normal ceruloplasmin level, and normal iron workup 
(serum iron, total iron-binding capacity, ferritin, and transferrin saturation).

Exclusion criteria included pregnant females, patients with history of drug intake likely to cause NASH (e.g., corticosteroids, hormone replacement therapy, and nonsteroidal anti-inflammatory drugs (NSAIDs)), patients with history of gastric bypass or extensive small bowel resection, and those with clinical, laboratory, and imaging features of acute hepatitis or liver cirrhosis. Moreover, patients with renal, respiratory, or cardiac failure and those who took vitamin D supplementation within 3 months prior to enrollment were excluded from the study.

All individuals participating in the study were subjected to complete medical history, full clinical examination, measurement of body weight $(\mathrm{kg})$, height $(\mathrm{m})$, BMI $\left(\mathrm{kg} / \mathrm{m}^{2}\right)$, pelvi-abdominal U/S, complete blood count (CBC), liver function tests (AST, ALT, total bilirubin, alkaline phosphatase, gamma glutamyl transferase, albumin), hepatitis markers (HBsAg and HCVAb), fasting blood sugar $(\mathrm{mg} / \mathrm{dl})$, fasting insulin level $(\mathrm{mU} / \mathrm{L})$, serum glycated $\mathrm{Hb}$ (HbA1c) (\%), serum creatinine (mg/ $\mathrm{dl})$, complete lipid profile (cholesterol $(\mathrm{mg} / \mathrm{dl})$, triglycerides $(\mathrm{mg} / \mathrm{dl})$, LDL $(\mathrm{mg} / \mathrm{dl})$, and HDL $(\mathrm{mg} / \mathrm{dl})$, and homeostasis model assessment of insulin resistance (HOMA-IR) was calculated using the formula (fasting plasma insulin $(\mathrm{mU} / \mathrm{L}) \times$ fasting plasma glucose $(\mathrm{mmol} /$ L)/22.5) [21]; NAFLD fibrosis score was calculated using the formula $(-1.675+0.037 \times$ age $($ year $)+0.094 \times$ BMI $\left(\mathrm{kg} / \mathrm{m}^{2}\right)+1.13 \times$ impaired fasting glucose (IFG)/diabetes $($ yes $=1$, no $=0)+0.99 \times \mathrm{AST} / \mathrm{ALT}$ ratio $-0.013 \times$ platelet $\left(\times 10^{9} / \mathrm{L}\right)-0.66 \times$ albumin $(\mathrm{g} / \mathrm{dL})[22]$, serum level of vitamin D (25-hydroxyvitamin D) ( $\mathrm{ng} / \mathrm{mL})$, and serum level of leptin $(\mathrm{ng} / \mathrm{ml})$.

Vitamin D (25-hydroxyvitamin D) was measured by radioimmunoassay (vitamin D total, Roche Diagnostics, Mannheim, German) according to the manufacturer's instructions. An electrochemiluminescence binding assay was performed using Elecsys immunoassay analyzers, with measurement ranging from 3.00 to $70.0 \mathrm{ng} / \mathrm{mL}$. Vitamin D status was defined based on the traditional classifications of "deficient" $\quad<20$ $\mathrm{ng} / \mathrm{mL})$, "insufficient" (20-30 ng/mL), and "sufficient" (> $30 \mathrm{ng} / \mathrm{mL})$ [23].

Quantitative determination of serum human leptin was performed using AssayMax Human Leptin ELISA Kit supplied by Assaypro LLC (Catalog No. EL2001-1). The AssayMax Human Leptin ELISA (Enzyme-Linked Immunosorbent Assay) kit was designed for detection of human leptin in plasma, serum, and cell culture samples. This assay employed a quantitative sandwich enzyme immunoassay technique. The reference value in normal weight/control subjects was $0.7-5.3 \mathrm{ng} / \mathrm{ml}$ in males and $3.3-18.3 \mathrm{ng} / \mathrm{ml}$ in females.
Patients with NASH were given vitamin $\mathrm{D}_{3}$ (cholecalciferol) supplements. The supplementation procedure for vitamin $\mathrm{D}_{3}$ was set at a $4000 \mathrm{IU}$ per day with main meal for 12 weeks. To examine the possible toxicity and hypervitaminosis that might arise from taking vitamin D supplements, serum concentrations of calcium at study baseline and end will be quantified. All anthropometric measurements, imaging studies, and laboratory blood tests were repeated after the end of treatment.

\section{Statistical analysis}

This is a prospective cohort study, where the researchers conceive and design the study, recruit subjects, and collect background data on all subjects before enrollment in the study. Data collection in this study was done using paper questionnaire and checklists in addition to physical examinations and observations during interviews with the subjects.

Data were collected, revised, coded, and entered into the statistical package for social science (IBM SPSS, version 20, Chicago, USA). Data was described as mean \pm standard deviation for quantitative variables and as number and percentage for qualitative variables. The comparison between two independent groups with quantitative data and parametric distribution was carried out by using the independent $t$ test. The probability of error $(p)$ was expressed as follows: $p$ value more than 0.05 : nonsignificant, $p$ value less than or equal to 0.05 : significant, and $p$ value less than 0.01 : highly significant.

\section{Results}

Forty patients with NASH were enrolled in this study in addition to forty age- and sex-matched healthy individuals which were taken as control. The NASH group included $21(52.5 \%)$ men and 19 (47.5\%) women while the control group included $24(60 \%)$ men and $16(40 \%)$ women. The mean age was $35.2 \pm 7.0$ years in the NASH group and $34.3 \pm 8.2$ years in the control group $(p=$ 0.5899). The demographic and characteristic data are listed in Table 1. The mean weight and BMI were 106.3 $\pm 15.6 \mathrm{~kg}$ and $35.7 \pm 5.7 \mathrm{~kg} / \mathrm{m}^{2}$ in the NASH group and $82.2 \pm 8.2 \mathrm{~kg}$ and $27.5 \pm 2.5 \mathrm{~kg} / \mathrm{m}^{2}$ in the control group respectively with a high statistically significant difference between both groups $(p<0.0001)$.

Subjects in the NASH group had higher levels than the control group as regards the following parameters: mean value in the NASH group/control group, diastolic blood pressure $(94.3 \pm 11.9 / 79.3 \pm 11.2 \mathrm{mmHg}), \mathrm{HbA1c}$ $(8.0 \pm 2.4 / 5.2 \pm 0.6 \%)$, fasting blood sugar $(165.6 \pm 62.0 /$ $101.7 \pm 22.9 \mathrm{mg} / \mathrm{dL})$, fasting insulin level $(24.2 \pm 3.0 / 17.0$ $\pm 2.3 \mu \mathrm{U} / \mathrm{ml})$, HOMA-IR $(1.8 \pm 0.7 / 0.8 \pm 0.2)$, ALT $(78.2$ $\pm 36.7 / 29.9 \pm 8.3 \mathrm{U} / \mathrm{L})$, AST $(108.6 \pm 85.6 / 25.5 \pm 7.5 \mathrm{U} /$ L), NAFLD fibrosis score $(-0.78 \pm 0.9 /-3.0 \pm 1.6)$, total cholesterol $(233.0 \pm 40.9 / 201.9 \pm 41.53 \mathrm{mg} / \mathrm{dL}), \mathrm{LDL}$ 
Table 1 Demographic, laboratory, and metabolic parameters of patients with the NASH and control groups

\begin{tabular}{|c|c|c|c|c|c|}
\hline Characteristics & $\mathrm{NASH}$ & Control & $\boldsymbol{t}$ value & $\boldsymbol{p}$ value & Significance \\
\hline Age (years) & $35.2 \pm 7.0$ & $34.3 \pm 8.2$ & 0.5412 & 0.5899 & NS \\
\hline Male & $21(52.5 \%)$ & $24(60 \%)$ & & & \\
\hline Female & 19 (47.5\%) & $16(40 \%)$ & & & \\
\hline Weight (kg) & $106.3 \pm 15.6$ & $82.2 \pm 8.2$ & 8.6455 & $<0.0001$ & HS \\
\hline Height (meter) & $1.7 \pm 0.08$ & $1.7 \pm 0.1$ & 0.0156 & 0.9876 & NS \\
\hline BMI $\left(\mathrm{kg} / \mathrm{m}^{2}\right)$ & $35.7 \pm 5.7$ & $27.5 \pm 2.5$ & 8.3947 & $<0.0001$ & HS \\
\hline $\mathrm{DBP}(\mathrm{mmHg})$ & $94.3 \pm 11.9$ & $79.3 \pm 11.2$ & 5.8312 & $<0.0001$ & HS \\
\hline Hepatomegaly & $20(50 \%)$ & $2(5 \%)$ & & & \\
\hline HbA1c (\%) & $8.0 \pm 2.4$ & $5.2 \pm 0.6$ & 7.2677 & $<0.0001$ & HS \\
\hline Hemoglobin (gm/dL) & $13.5 \pm 1.5$ & $13.2 \pm 1.3$ & 0.8487 & 0.3986 & NS \\
\hline Platelet $\left(\times 10^{3} / \mu \mathrm{L}\right)$ & $288.5 \pm 114.9$ & $322.1 \pm 118.7$ & 1.2836 & 0.2031 & NS \\
\hline FBS (mg/dL) & $165.6 \pm 62.0$ & $101.7 \pm 22.9$ & 6.1141 & $<0.0001$ & HS \\
\hline Fasting insulin $(\mu \mathrm{U} / \mathrm{ml})$ & $24.2 \pm 3.0$ & $17.0 \pm 2.3$ & 12.1379 & $<0.0001$ & HS \\
\hline HOMA-IR & $1.8 \pm 0.7$ & $0.8 \pm 0.2$ & 8.8731 & $<0.0001$ & HS \\
\hline Creatinine (mg/dL) & $0.9 \pm 0.2$ & $0.9 \pm 0.3$ & 2.6252 & 0.8252 & NS \\
\hline ALT (U/L) & $78.2 \pm 36.7$ & $29.9 \pm 8.3$ & 8.1260 & $<0.0001$ & HS \\
\hline AST (U/L) & $108.6 \pm 85.6$ & $25.5 \pm 7.5$ & 6.1183 & $<0.0001$ & HS \\
\hline Albumin (gm/dL) & $3.8 \pm 0.8$ & $4.6 \pm 0.6$ & 4.7217 & $<0.0001$ & HS \\
\hline NAFLD fibrosis score & $-0.78 \pm 0.9$ & $-3.0 \pm 1.6$ & 7.8602 & $<0.0001$ & HS \\
\hline TCHOL (mg/dL) & $233.0 \pm 40.9$ & $201.9 \pm 41.53$ & 3.3796 & 0.0011 & HS \\
\hline LDL (mg/dL) & $117.5 \pm 41.6$ & $95.35 \pm 31.1$ & 2.7022 & 0.0084 & HS \\
\hline $\mathrm{HDL}(\mathrm{mg} / \mathrm{dL})$ & $48.5 \pm 7.59$ & $64.58 \pm 8.2$ & 9.1398 & $<0.0001$ & HS \\
\hline Triglycerides (mg/dL) & $229.7 \pm 62.1$ & $142.9 \pm 36.3$ & 7.6224 & $<0.0001$ & HS \\
\hline ALP (mg/dL) & $70.4 \pm 7.3$ & $58.2 \pm 6.9$ & 7.6925 & $<0.0001$ & HS \\
\hline GGT (U/L) & $43.3 \pm 24.5$ & $25.1 \pm 7.1$ & 4.5140 & $<0.0001$ & HS \\
\hline Total bilirubin (mg/dL) & $1.1 \pm 0.4$ & $1.1 \pm 1.1$ & 0.2240 & 0.8234 & NS \\
\hline Vitamin D (ng/ml) & $15.6 \pm 6.6$ & $21.0 \pm 6.5$ & 3.7323 & 0.0004 & HS \\
\hline Leptin (ng/ml) & $35.9 \pm 28.4$ & $10.1 \pm 1.8$ & 5.7407 & $<0.0001$ & HS \\
\hline
\end{tabular}

$(117.5 \pm 41.6 / 95.35 \pm 31.1 \mathrm{mg} / \mathrm{dL})$, triglycerides $(229.7 \pm$ $62.1 / 142.9 \pm 36.3 \mathrm{mg} / \mathrm{dL})$, alkaline phosphates $(70.4 \pm$ $7.3 / 58.2 \pm 6.9 \mathrm{mg} / \mathrm{dL})$, and gamma glutamyl transferase $(43.3 \pm 24.5 / 25.1 \pm 7.1 \mathrm{U} / \mathrm{L})$ with significant statistical difference between both groups $(p<0.0001)$.

Twenty patients $(50 \%)$ in the NASH group had hepatomegaly by abdominal ultrasonography in comparison to two subjects $(5 \%)$ in the control group. There was no significant difference between the two groups regarding serum hemoglobin concentration, platelet count, serum creatinine, and total bilirubin.

Serum albumin level and HDL were significantly higher $(p<0.0001)$ in the control group $(4.6 \pm 0.6 \mathrm{gm} / \mathrm{dL}, 64.58$ $\pm 8.2 \mathrm{mg} / \mathrm{dL}$ respectively) than in patients with NASH (3.8 $\pm 0.8 \mathrm{gm} / \mathrm{dL}, 48.5 \pm 7.59 \mathrm{mg} / \mathrm{dL}$ respectively).

There was a statistically significant difference $(p<$ 0.0001 ) between both groups as regards serum level of vitamin D and serum leptin. Patients with NASH had lower serum vitamin D level $(15.6 \pm 6.6 \mathrm{ng} / \mathrm{ml})$ and higher serum leptin level $(35.9 \pm 28.4 \mathrm{ng} / \mathrm{ml})$ than the control group where the mean values of vitamin $\mathrm{D}$ and serum leptin were $21.0 \pm 6.5 \mathrm{ng} / \mathrm{ml}$ and $10.1 \pm 1.8 \mathrm{ng} / \mathrm{ml}$ respectively.

All patients with NASH were given vitamin $\mathrm{D}_{3}$ supplements as tablets. Each tablet contained $1000 \mathrm{IU}$ vitamin $\mathrm{D}_{3}$ (cholecalciferol). Every patient took 4 tablets (4000 IU) every day with main meal for 12 weeks. All demographic, laboratory, and clinical characteristics of the patients were measured again at the end of the 12th week of treatment and were represented in Table 2 .

Following NASH treatment with vitamin $\mathrm{D}_{3}$ supplements, there was a statistically significant $(p<0.05)$ reduction in HbA1c $(6.8 \pm 1.3 \%)$, fasting blood sugar (136.1 \pm $32.7 \mathrm{mg} / \mathrm{dL})$, fasting insulin level $(22.9 \pm 1.8 \mu \mathrm{U} / \mathrm{ml})$, HOMA-IR (1.4 \pm 0.4$)$, ALT $(55.3 \pm 21.3 \mathrm{U} / \mathrm{L})$, AST $(73.1$ $\pm 54.2 \mathrm{U} / \mathrm{L})$, triglycerides $(203.6 \pm 49.8 \mathrm{mg} / \mathrm{dL})$, alkaline 
Table 2 Association of vitamin D supplementation with different demographic, laboratory, and metabolic parameters of patients with NASH

\begin{tabular}{|c|c|c|c|c|c|}
\hline Characteristics & Before treatment & After treatment & $\boldsymbol{t}$ value & $\boldsymbol{p}$ value & Significance \\
\hline Weight (kg) & $106.3 \pm 15.6$ & $106.0 \pm 15.9$ & 0.0924 & 0.9266 & NS \\
\hline BMI $\left(\mathrm{kg} / \mathrm{m}^{2}\right)$ & $35.7 \pm 5.7$ & $35.6 \pm 5.7$ & 0.0901 & 0.9284 & NS \\
\hline $\mathrm{DBP}(\mathrm{mmHg})$ & $94.3 \pm 11.9$ & $91.5 \pm 11.5$ & 1.0553 & 0.2946 & NS \\
\hline HbA1c (\%) & $8.0 \pm 2.4$ & $6.8 \pm 1.3$ & 2.8558 & 0.0055 & 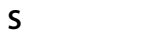 \\
\hline Hemoglobin (gm/dL) & $13.5 \pm 1.5$ & $13.3 \pm 1.2$ & 0.6176 & 0.5386 & NS \\
\hline Platelet $\left(\times 10^{3} / \mu \mathrm{L}\right)$ & $288.5 \pm 114.9$ & $285.2 \pm 98.3$ & 0.1412 & 0.8881 & NS \\
\hline FBS (mg/dL) & $165.6 \pm 62.0$ & $136.1 \pm 32.7$ & 2.6637 & 0.0094 & $S$ \\
\hline Fasting insulin $(\mu \mathrm{U} / \mathrm{ml})$ & $24.2 \pm 3.0$ & $22.9 \pm 1.8$ & 2.3090 & 0.0236 & $S$ \\
\hline HOMA-IR & $1.8 \pm 0.7$ & $1.4 \pm 0.4$ & 3.1134 & 0.0026 & $S$ \\
\hline Creatinine (mg/dL) & $0.9 \pm 0.2$ & $0.9 \pm 0.3$ & 0.2439 & 0.8080 & NS \\
\hline ALT (U/L) & $78.2 \pm 36.7$ & $55.3 \pm 21.3$ & 3.4135 & 0.0010 & 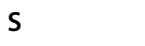 \\
\hline AST (U/L) & $108.6 \pm 85.6$ & $73.1 \pm 54.2$ & 2.2143 & 0.0297 & 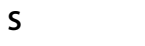 \\
\hline Albumin (gm/dL) & $3.8 \pm 0.8$ & $4.2 \pm 0.7$ & 2.2273 & 0.0288 & $S$ \\
\hline NAFLD fibrosis score & $-0.78 \pm 0.9$ & $-0.9 \pm 1.1$ & 0.9934 & 0.3236 & NS \\
\hline TCHOL (mg/dL) & $233.0 \pm 40.9$ & $226.5 \pm 38.2$ & 0.7431 & 0.4596 & NS \\
\hline LDL (mg/dL) & $117.5 \pm 41.6$ & $129.8 \pm 34.7$ & 1.4286 & 0.1571 & NS \\
\hline $\mathrm{HDL}(\mathrm{mg} / \mathrm{dL})$ & $48.5 \pm 7.59$ & $48.1 \pm 8.1$ & 0.1858 & 0.8531 & NS \\
\hline Triglycerides (mg/dL) & $229.7 \pm 62.1$ & $203.6 \pm 49.8$ & 2.0728 & 0.0415 & 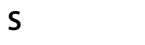 \\
\hline ALP (mg/dL) & $70.4 \pm 7.3$ & $63.7 \pm 7.9$ & 3.9422 & 0.0002 & $S$ \\
\hline GGT (U/L) & $43.3 \pm 24.5$ & $35.1 \pm 8.7$ & 2.0069 & 0.0482 & 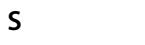 \\
\hline Total bilirubin (mg/dL) & $1.1 \pm 0.4$ & $1.1 \pm 0.1$ & 0.2267 & 0.8212 & NS \\
\hline Vitamin D (ng/ml) & $15.6 \pm 6.6$ & $33.0 \pm 7.6$ & 11.0335 & $<0.0001$ & 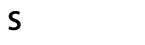 \\
\hline Leptin (ng/ml) & $35.9 \pm 28.4$ & $23.5 \pm 12.9$ & 2.5129 & 0.0140 & 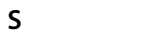 \\
\hline
\end{tabular}

phosphatase $(63.7 \pm 7.9 \mathrm{mg} / \mathrm{dL})$, and gamma glutamyl transferase $(35.1 \pm 8.7 \mathrm{U} / \mathrm{L})$ and a statistically significant $(p<0.05)$ increase in serum albumin level $(4.2 \pm 0.7 \mathrm{gm} / \mathrm{dL})$.

No significant changes were noted before and after vitamin $\mathrm{D}_{3}$ treatment regarding mean body weight, $\mathrm{BMI}$, diastolic blood pressure, hemoglobin concentration, platelet count, serum creatinine, NAFLD fibrosis score, serum cholesterol, LDL, HDL, and total bilirubin.

There was a statistically significant increase $(p<$ $0.0001)$ in serum vitamin $\mathrm{D}_{3}$ level after treatment (33.0 $\pm 7.6 \mathrm{ng} / \mathrm{ml})$ than before treatment $(15.6 \pm 6.6 \mathrm{ng} / \mathrm{ml})$. Moreover, serum leptin level decreased significantly ( $p=$ 0.0140) in patients with NASH following treatment with vitamin $\mathrm{D}_{3}$ with mean value of $23.5 \pm 12.9 \mathrm{ng} / \mathrm{ml}$ compared to $35.9 \pm 28.4 \mathrm{ng} / \mathrm{ml}$ before treatment.

\section{Discussion}

Non-alcoholic fatty liver disease (NAFLD) comprises a whole spectrum of diseases, including simple steatosis and steatohepatitis (NASH) which can progress to liver fibrosis, cirrhosis, and hepatocellular carcinoma. NAFLD is highly associated with obesity, insulin resistance, and metabolic syndrome, and it is estimated to affect about $20-40 \%$ of the general population in developed countries [24].

Vitamin D has long been regarded as a regulatory factor for phospho-calcium metabolism and bone homeostasis. However, many studies have shown more properties, namely immunomodulatory role [25], involvement in cellular differentiation and proliferation [26], hormone secretion [27], and anti-inflammatory and antifibrotic effects [28]. All these roles support the importance of maintaining optimal vitamin D levels.

Vitamin D deficiency constitutes a largely unrecognized epidemic in many populations worldwide and has been reported in all age groups including healthy children, young adults, middle-aged, and elderly adults [29].

In this study, we measured different demographic, laboratory, and metabolic parameters in forty patients with NASH and compared them with those of age- and sex-matched forty healthy individuals as the control group. Then, vitamin D (4000 IU/day) was given to the NASH group for 12 weeks. All demographic, laboratory, and metabolic parameters including serum leptin level were repeated after the end of treatment. Then, we demonstrated the association of vitamin D supplementation 
with serum leptin and metabolic parameters in patients with NASH.

In this study, we found that patients with NASH had higher body weight and BMI than the control. Many former studies concluded that obesity is a condition most often associated with NASH as 69 to $100 \%$ of patients with NASH were also obese. Obesity is associated with increased FFA delivery to the liver, increased FFA synthesis within the liver, insufficient beta-oxidation of FFA, and insufficient very low-density lipoprotein synthesis or secretion [30].

This study concluded that insulin resistance and dyslipidemia were more common in NASH with higher levels of $\mathrm{HbA1c}$, fasting blood glucose, fasting insulin level, HOMA-IR, cholesterol, LDL, and lower levels of HDL compared to the control. Insulin resistance is associated with various metabolic abnormalities especially hyperglycemia, hypertriglyceridemia, low HDL cholesterol, and high levels of LDL leading to the concept of "metabolic syndrome" [30]. When resistance to antilipolytic action of insulin is present, fatty acids are mobilized more rapidly from visceral (central) than from subcutaneous (peripheral) fat and drained directly to the liver via the portal vein. Excessive intracellular concentrations of fatty acids may be toxic and lead to oxidative stress and thus contribute to NASH [31].

In this study, patients with NASH have significantly low vitamin D levels. This agrees with previous studies that noted high prevalence of hypovitaminosis D in patients with NAFLD [19]. This may be explained by the increased amount of adipose tissue in which the vitamin $\mathrm{D}$ is distributed in obese patients with $\mathrm{NASH}$; this will decrease the circulating serum of vitamin $D$ level [32]. Another explanation could be related to sedentary lifestyle, poor micro-nutrient nutrition, and lack of exposure to sunlight [33]. Moreover, in view of the bile acid-dependent uptake of vitamin $\mathrm{D}$, it is reasonable to expect an association between vitamin D status and both cholestatic and noncholestatic chronic liver diseases [19].

The study noted that serum leptin levels were raised in both men and women with NASH compared with age- and sex-matched controls. Several factors could contribute to increased serum leptin levels in NASH. Hyperleptinemia occurs in inflammatory disorders and has been attributed to cytokines such as tumor necrosis factor- $\alpha$ (TNF- $\alpha$ ), which is also increased in NASH as TNF- $\alpha$ gene is overexpressed in adipose tissue of obese NASH subjects. Chronic hyperinsulinemia, which is especially relevant in the setting of NASH, is associated with persistent hyperleptinemia. Moreover, leptin also correlates with serum c-peptide. In patients with NASH, c-peptide is not significantly cleared by the liver [9].
Following vitamin D supplementation in a dose of 4000 IU/day for 12 weeks, there was significant improvement of NASH. There was significant decrease in ALT, AST, ALP, GGT, and NAFLD fibrosis score. Previous studies noticed significant improvement in serum levels of ALT in NASH patients who took standard medical treatment (SMT) together with vitamin D when compared with others who took SMT alone [20]. Vitamin D was effective in liver enzyme reduction in another study [34]. Vitamin D-mediated improvement in insulin secretion results in decreased adipose tissue inflammation with decreased hepatic inflammation and fibrosis via the regulation of the vitamin $\mathrm{D}$ receptor and several cytokines such as interleukin 6 , TNF- $\alpha$, and adiponectin [18]. New evidence revealed that vitamin D can prevent hepatic stellate cell (HSC) activation which increases cellular transformation and proliferation [35].

In this study, vitamin D treatment significantly decreased insulin resistance in NASH patients. Values of fasting blood sugar, fasting insulin level, and HOMA-IR were significantly decreased after treatment. Vitamin D, through its effect on peroxisome proliferator-activated receptor, can modulate FFA metabolism and reduce FFA-induced insulin resistance in bloodstream [34]. Other studies reported significant reduction in FBS, insulin, and HOMA-IR following vitamin D supplementation in NASH [36]. The decreased production of TNF- $\alpha$ and increasing adiponectin during therapy with vitamin $\mathrm{D}$ is expected to improve the underlying IR in patients with NASH [19].

Serum triglycerides (TGs) decreased after treatment with vitamin $\mathrm{D}$ while there were no significant change in levels of cholesterol, LDL, and HDL. Foroughi et al. [37] assessed vitamin D effect on TGs in patients with NASH. They stated that, after 10 weeks of vitamin D treatment (50,000 IU/week), a significant decrease in serum TGs was seen when compared with baseline values. Hariri and Zohdi [36] also found that vitamin D supplementation might improve lipid profile and inflammatory mediators (like C-reactive protein) in NASH patients when compared with placebo.

One of the main physiological roles of leptin is to prevent lipid accumulation in nonadipose sites, such as the myocardium, skeletal muscle, pancreas, and liver, a concept referred to as "lipotoxicity" [38]. In this study, treatment with vitamin $\mathrm{D}$ has led to significant decrease in serum leptin level. This agreed with previous studies which confirmed that vitamin D level was negatively correlated with leptin in patients with NASH [39]. Other studies also reported vitamin D-mediated inhibition of serum leptin [40].

\section{Conclusion}

Vitamin D deficiency is highly prevalent among NASH patients, and this deficiency is related to the degree of 
liver function and degree of fibrosis. Vitamin D supplementation in patients with NASH in a dose of $4000 \mathrm{IU} /$ day for 12 weeks improves severity of hepatic inflammation, decreases insulin resistance, improves glycemic control, corrects dyslipidemia, and protects against lipotoxicity by inhibition of serum leptin.

\section{Recommendation}

Our findings regarding the relationship between vitamin D deficiency and NASH suggest that taking vitamin D supplements should be a therapeutic option for patients with NASH. Additional studies are recommended to determine the association of variable doses and duration of vitamin D treatment with histopathological, laboratory, and clinical aspects in patients with NASH.

\section{Abbreviations}

NAFLD: Non-alcoholic steatohepatitis; NASH: Non-alcoholic steatohepatitis; MS: Metabolic syndrome; BMI: Body mass index; DBP: Diastolic blood pressure; FBS: Fasting blood sugar; HOMA-IR: Homeostasis model assessment of insulin resistance; ALT: Alanine transferase; AST: Aspartate transferase; LDL: Low-density lipoprotein; HDL: High-density lipoprotein; TCHOL: Total cholesterol; ALP: Alkaline phosphatase; GGT: Gamma glutamyl transferase; TNF-a: Tumor necrosis factor-a; TGs: Triglycerides

\section{Acknowledgements}

The authors express their gratitude to all members of the Hepatology and Gastroenterology Department, Faculty of Medicine, Ain Shams University, for their valuable participation.

\section{Authors' contributions}

AS Abohalima has made substantial contribution to the conception and design in this study by collecting, revising, and coding the data. He shared in writing the manuscript. HH Kaisar has made substantial contribution to the analysis and interpretation in this study. He revised and drafted the work. He performed the statistical analysis of the data and shared in writing the manuscript. All authors have read and approved the submitted version of manuscript. Each author agreed to be personally accountable for his own contributions and ensured that questions related to the accuracy or integrity of any part of the work are appropriately investigated and resolved.

\section{Funding}

The study was funded by the authors.

\section{Availability of data and materials}

The datasets used and analyzed during the current study are available from the corresponding author on reasonable request.

\section{Ethics approval and consent to participate}

All procedures performed in this study were in accordance with the ethical standards of Ain Shams University research committee and with the 1964 Helsinki declaration and its later amendments. Ethics committee's reference number 000017585 . An informed written consent was obtained from all participants included in this study.

\section{Consent for publication}

Not applicable

\section{Competing interests}

The authors declare that they have no competing interests in this section

Received: 7 May 2020 Accepted: 28 July 2020

Published online: 05 August 2020

\section{References}

1. Sattar N, Forrest E, Preiss D (2014) Non-alcoholic fatty liver disease. BMJ (Clin Res Ed) 349:94596
2. Sanyal AJ (2002) AGA technical review on nonalcoholic fatty liver disease. Gastroenterology 123:1705-1725

3. Duseja A, Singh SP, Saraswat VA et al (2015) Non-alcoholic fatty liver disease and metabolic syndrome-position paper of the Indian National Association for the study of the liver, Endocrine Society of India, Indian College of Cardiology and Indian Society of gastroenterology. J Clin Exp Hepatol 5:51-68

4. Torres DM, Harrison SA (2008) Diagnosis and therapy of nonalcoholic steatohepatitis. Gastroenterology 134:1682-1698

5. Bellentani S (2017) The epidemiology of non-alcoholic fatty liver disease. Liver Int 37(Suppl 1):81-84

6. Chalasani N, Younossi Z, Lavine JE, Diehl AM, Brunt EM, Cusi K, Charlton M, Sanyal AJ (2012) The diagnosis and management of nonalcoholic fatty liver disease: practice guideline by the American Gastroenterological Association, American Association for the Study of Liver Diseases, and American College of Gastroenterology. Gastroenterology 142(7):1592-1609

7. Roubos EW, Dahmen M, Kozicz T et al (2012) Leptin and the hypothalamopituitary-adrenal stress axis. Gen Comp Endocrino 177(1):28-36

8. Belgardt BF, Brüning JC (2010) CNS leptin and insulin action in the control of energy homeostasis. Ann N Y Acad Sci 1212:97-113

9. Shivakumar Chitturi, Geoffrey Farrell, Linda Frost, Adamandia Kriketos, Rita Lin, Christopher Liddle, Dev Samarasinghe and Jacob George (2002) Serum leptin in NASH correlates with hepatic steatosis but not fibrosis: a manifestation of lipotoxicity? Hepatology; August Vol. 36, No. 2:403-408

10. Bruyere O, Malaise O, Neuprez A et al (2007) Prevalence of vitamin D inadequacy in European postmenopausal women. Curr Med Res Opin 23: 1939-1944

11. Abramovitch S, Dahan-Bachar L, Sharvit E, Weisman Y, Ben Tov A, Brazowski $E$ et al (2011) Vitamin D inhibits proliferation and profibrotic marker expression in hepatic stellate cells and decreases thioacetamide-induced liver fibrosis in rats. Gut 60:1728-1737

12. Gagnon C, Lu ZX, Magliano DJ et al (2012) Low serum 25-hydroxyvitamin D is associated with increased risk of the development of the metabolic syndrome at five years: results from a national, population-based prospective study (the Australian diabetes, obesity and lifestyle study: AusDiab). J Clin Endocrinol Metab 97:1953-1961

13. Pittas AG, Lau J, Hu FB et al. (2007) The role of vitamin D and calcium in type 2 diabetes. A systematic review and meta-analysis. J Clin Endocrinol Metab.; 92: 2017-2029.

14. Scragg R, Sowers M, Bell C (2004) Serum 25-hydroxyvitamin D, diabetes, and ethnicity in the third National Health and nutrition examination survey. Diabetes Care 27:2813-2818

15. Parikh SJ, Edelman M, Uwaifo Gl, Freedman RJ, Semega-Janneh M, Reynolds J, Yanovski JA (2004) The relationship between obesity and serum 1,25dihydroxy vitamin D concentrations in healthy adults. J Clin Endocrinol Metab 89:1196-1199

16. Snijder MB, van Dam RM, Visser M, Deeg DJ, Dekker JM, Bouter LM, Seidel JC, Lips P (2005) Adiposity in relation to vitamin D status and parathyroid hormone levels: a population-based study in older men and women. J Clin Endocrinol Metab 90:4119-4123

17. Zhou QG, Hou FF, Guo ZJ et al (2008) 1,25-Dihydroxyvitamin D improved the free fatty-acid-induced insulin resistance in cultured C2C12 cells. Diabetes Metab Res Rev 24:459-464

18. Eliades M, Spyrou E (2015) Vitamin D: a new player in non-alcoholic fatty liver disease? World J Gastroenterol 21(6):1718-1727

19. Sakpal M, Satsangi S, Mehta M, Duseja A, Bhadada S, Das A, Dhiman RK, Chawla YK. (2017) Vitamin D supplementation in patients with nonalcoholic fatty liver disease: a randomized controlled trial. J Gastroenterol Hepatol, 1; 62-67.

20. Kwok RM, Torres DM, Harrison SA (2013) Vitamin D and nonalcoholic fatty liver disease (NAFLD): is it more than just an association? Hepatology 58: $1166-1174$

21. Matthews DR, Hosker JP, Rudenski AS et al (1985) Homeostasis model assessment: insulin resistance and beta-cell function from fasting plasma glucose and insulin concentrations in man. Diabetologia 28: $412-419$

22. Angulo P, Hui JM, Marchesini G et al (2007) The NAFLD fibrosis score: a noninvasive system that identifies liver fibrosis in patients with NAFLD. Hepatology 45:846-854

23. Holick MF (2009) Vitamin D status: measurement, interpretation, and clinical application. Ann Epidemiol 19:73-78 
24. Fabbrini E, Sullivan S, Klein S (2010) Obesity and nonalcoholic fatty liver disease: biochemical, metabolic and clinical implications. Hepatology 51(2): 679-689

25. Chen S, Sims GP, Chen XX, Gu YY, Chen S, Lipsky PE (2007) Modulatory effects of 1,25 dihydroxyvitamin D3 on human B cell differentiation. J Immunol 179(3):1634-1647

26. Bikle B (2009) Nonclassic actions of vitamin D. J Clin Endocrinol Metab 94(1): 26-34

27. Li YC, King J, Wei M, Chen ZF, Liu SQ, Cao LP (2002) 1,25-Dihydroxyvitamin $D(3)$ is a negative endocrine regulator of the renin-angiotensin system. J Clin Invest 110(2):229-238

28. Beilfuss A, Sowa JP, Sydor S, Beste M, Bechmann LP, Schlattjan M, Syn WK, Wedemeyer I, Mathé Z, Jochum C, Gerken G, Gieseler RK, Canbay A (2015) Vitamin D counteracts fibrogenic TGF- $\beta$ signalling in human hepatic stellate cells both receptor dependently and independently. Gut 64(5):791-799

29. Gordon CM, DePeter KC, Feldman HA et al (2004) Prevalence of vitamin D deficiency among healthy adolescents. Arch Pediatr Adolesc Med 158:531537

30. Howard BV. (1999) Insulin resistance and lipid metabolism. Am J Cardiol, 84 (Suppl 1A), $28 \mathrm{~J}-32 \mathrm{~J}$.

31. Sheth SG, Gordon FD, Chopra S (1997) Nonalcoholic steatohepatitis. Ann Intern Med 126:137-145

32. Wortsman J, Matsuoka LY, Chen TC, Lu Z, Holick MF (2000) Decreased bioavailability of vitamin D in obesity. Am J Clin Nutr 72(3):690-693

33. Bradlee ML, Singer MR, Qureshi MM, Moore LL (2010) Food group intake and central obesity among children and adolescents in the third National Health and nutrition examination survey (NHANES III). Public Health Nutr 13(6):797-805

34. Hariri M, Zohdi S (2019) Effect of vitamin D on non-alcoholic fatty liver disease: a systematic review of randomized controlled clinical trials. Int J Prev Med 10:14

35. Seydel S, Beilfuss A, Kahraman A, Aksoy K, Gerken G, Akkiz H et al (2011) Vitamin $\mathrm{D}$ ameliorates stress ligand expression elicited by free fatty acids in the hepatic stellate cell line LX-2. Turk J Gastroenterol 22:400-407

36. Lorvand Amiri H, Agah S, Tolouei Azar J, Hosseini S, Shidfar F, Mousavi SN et al (2017) Effect of daily calcitriol supplementation with and without calcium on disease regression in non-alcoholic fatty liver patients following an energy-restricted diet: randomized, controlled, double-blind trial. Clin Nutr 36:1490-1497

37. Foroughi M, Maghsoudi Z, Ghiasvand R, Iraj B, Askari G (2014) Effect of vitamin $D$ supplementation on C-reactive protein in patients with nonalcoholic fatty liver. Int J Prev Med 5:969-975

38. Unger RH, Orci L (2001) Diseases of liporegulation: new perspective on obesity and related disorders. FASEB J 15:312-321

39. Chen L-W, Chien C-H, Kuo S-F, Yu C-Y, Lin C-L, Chien R-N (2019) Low vitamin $\mathrm{D}$ level was associated with metabolic syndrome and high leptin level in subjects with nonalcoholic fatty liver disease: a community-based study. BMC Gastroenterol 19:126. https://doi.org/https://doi.org/10.1186/ s12876-019-1040-y

40. Hajimohammadi M, Shab-Bidar S, Neyestani TR (2017) Vitamin D and serum leptin: a systematic review and meta-analysis of observational studies and randomized controlled trials. Eur J Clin Nutr 71:1144-1153

\section{Publisher's Note}

Springer Nature remains neutral with regard to jurisdictional claims in published maps and institutional affiliations.

\section{Submit your manuscript to a SpringerOpen ${ }^{\circ}$ journal and benefit from:}

- Convenient online submission

- Rigorous peer review

- Open access: articles freely available online

- High visibility within the field

- Retaining the copyright to your article

Submit your next manuscript at $\boldsymbol{\nabla}$ springeropen.com 